Brazilian Journal

of Chemical

ISSN 0104-6632

Engineering

\title{
FED-BATCH BIOREACTOR PROCESS WITH RECOMBINANT Saccharomyces cerevisiae GROWING ON CHEESE WHEY
}

\author{
R. Rech and M. A. Z. Ayub* \\ Food Science and Technology Institute, Federal University of Rio Grande do Sul \\ State, Av. Bento Gonçalves 9500, PO Box 15090, \\ ZC 91501-970, Porto Alegre - RS, Brazil. \\ E-mail: mazayub@ufrgs.br
}

(Received: June 6, 2005 ; Accepted: June 2, 2006)

\begin{abstract}
Saccharomyces cerevisiae strain W303 was transformed with two yeast integrative plasmids containing Kluyveromyces lactis LAC4 and LAC12 genes that codify $\beta$-galactosidase and lactose permease respectively. The BLR030 recombinant strain was selected due to its growth and $\beta$-galactosidase production capacity. Different culture media based on deproteinized cheese whey (DCW) were tested and the best composition (containing DCW, supplemented with yeast extract $1 \%$, and peptone $3 \%(\mathrm{w} / \mathrm{v})$ ) was chosen for bioreactor experiments. Batch, and fed-batch cultures with linear ascending feeding for 25 (FB25), 35 (FB35), and 50 (FB50) hours, were performed. FB35 and FB50 produced the highest $\beta$-galactosidase specific activities (around 1,800 U/g cells), and also the best productivities (180 U/L.h). Results show the potential use of fed-batch cultures of recombinant $S$. cerevisiae on industrial applications using supplemented whey as substrate.
\end{abstract}

Keywords: Recombinant Saccharomyces cerevisiae; $\beta$-galactosidase; Cheese-whey; Fed-batch cultivation.

\section{INTRODUCTION}

Recombinant technology applied to microorganisms, which are able to grow in large-scale bioreactors, can be used to obtain large quantities of protein, otherwise difficult or impossible to obtain. Saccharomyces cerevisiae, as a host micro-organism for the expression of heterologous proteins, has been particularly attractive for this purpose. This yeast is generally recognized as a safe micro-organism (GRAS), lacking endotoxins and lytic viruses, being able to perform many post-translational modifications, including glycosylation, acylation and folding of proteins (Alberghina et al., 1991). S. cerevisiae has been used as a host micro-organism to produce different heterologous proteins such as $\beta$-galactosidase (Cheng et al., 1997), glucoamylase
(Hardjito et al., 1993), $\alpha-2,6(\mathrm{~N})$-sialyltransferase (Borsig et al., 1995), antithrombotic hirudin (Kim et al., 2003), sporamin (Chen et al., 2003), Closterium sex pheromone (Sekimoto, 2002), cutinase (Calado et al., 2002), Rhizopus oryzae lipase (Ueda et al., 2002), capsid proteins of human polyomaviruses BK and JC (Hale et al., 2002), human interleukin-18 (Lim et al., 2002), $\alpha_{1}$-antitrypsin (Tamer and Chisti, 2001), human XPA and XRCC1 DNA repair proteins (Pushnova et al., 2001), Aspergillus ficuum endoinulinase (Park et al., 2001).

Some studies for the production of recombinant protein by $S$. cerevisiae report the use of fed-batch cultivations to obtain higher productivity. Different feeding methodologies have been tried, such as constant feeding (Hardjito et al., 1993; Belem and Lee, 1999) or exponential feeding (Gombert and

*To whom correspondence should be addressed 
Kilikian, 1997; Shin et al., 1998) in order to obtain constant specific growth rates. Other studies rely on sophisticated systems, requiring fine instrumentation, such as on-line glucose and ethanol concentrations control (Alberghina et al., 1991; Horn et al., 1996). Other methodologies have been successfully developed based upon $\mathrm{pH}$ controlled feeding (Porro et al., 1991); dissolved oxygen controlled feeding for Kluyveromyces marxianus (Barberis and Segovia, 1997); off-line glucose measure (Patkar and Seo, 1992); and dissolved oxygen measure with the MSUR (maximum substrate uptake rate) for $S$. cerevisiae and K. marxianus (Oh et al., 1998, Nor et al., 2001).

Cheese whey, which is a by-product of cheese making, represents $85-95 \%$ of the original milk volume and retains $55 \%$ of the milk nutrients, mainly lactose $(4.5-5 \%(\mathrm{w} / \mathrm{v}))$ and proteins $(0.6-0.8$ $\% \quad(\mathrm{w} / \mathrm{v}))$. However, since it contains low concentration of solids $(6-7 \%(\mathrm{w} / \mathrm{v}))$, cheese whey usually is considered an effluent. Despite the fact that many technologies have been developed for cheese whey utilization, nearly half of worldwide cheese-whey production is still discarded as effluents (González-Siso, 1996). According to the USDA, the Brazilian cheese-whey production is increasing annually, reaching more than 550,000 tons in 2002 (USDA-NASS, 2002), generating approximately 4 millions tons of cheese-whey.

The fed-batch cultures of $S$. cerevisiae described so far by the literature, besides sophisticated controls, use defined or selective media, mainly with glucose as the carbon source. This work aimed to develop simple linear strategies of feeding for fed-batch cultures of recombinant $S$. cerevisiae, using an undefined culture medium based on supplemented cheese whey as carbon source.

\section{MATERIALS AND METHODS}

\section{Chemicals}

Except where otherwise indicated, all chemicals used were of analytical grade, bought from Sigma (St. Louis, USA) or Merck (Darmstadt, Germany).

\section{Yeast Strain}

S. cerevisiae W303 (Mata ade2-1 his3-11 leu2-3,112 ura3-1 trp1) was kindly provided by Prof.
JAP Henriques (Biotechnology Centre, UFRGS, Porto Alegre, Brazil) and maintained on agar-plates containing YPD medium (Saffi, et al., 2001).

\section{Plasmids}

Plasmids pMR4 and pMR11 were kindly provided by Dr. J Polaina (Instituto de Agroquímica y Tecnología de Alimentos, Valencia, Spain). These plasmids contain leu2-d gene, a rDNA locus sequence and the genes LAC4 and LAC12 under the control of a CYC-GAL promoter. The genes LAC4 and LAC12 code $\beta$-galactosidase and lactose-permease of Kluyveromyces lactis respectively (Rubio-Teixeira et al., 2000).

\section{Yeast Transformation}

Strain W303 was co-transformed with plasmids pMR4 and pMR11 by high efficiency lithium-acetate technique (Agatep et al., 1998) and incubated on lactose SD-agar plates at $30^{\circ} \mathrm{C}$ for 5 days.

\section{Culture Media}

Selective media were made up of lactose, glucose or maltose SD-agar plates supplemented with amino acids (lactose, glucose or galactose $20 \mathrm{~g} / \mathrm{L}$, yeast nitrogen base without amino acids $6.7 \mathrm{~g} / \mathrm{L}$, adenine 20 $\mathrm{mg} / \mathrm{L}$, histidine $20 \mathrm{mg} / \mathrm{L}$, tryptophan $20 \mathrm{mg} / \mathrm{L}$, uracil $20 \mathrm{mg} / \mathrm{L}$. Complex media were YPD (glucose $20 \mathrm{~g} / \mathrm{L}$, peptone $20 \mathrm{~g} / \mathrm{L}$, yeast extract $10 \mathrm{~g} / \mathrm{L}$ ) or YPL (lactose $40 \mathrm{~g} / \mathrm{L}$, peptone $20 \mathrm{~g} / \mathrm{L}$, yeast extract $10 \mathrm{~g} / \mathrm{L}$ ).

To obtain deproteinized cheese whey (DCW), 70 $\mathrm{g} / \mathrm{L}$ or $210 \mathrm{~g} / \mathrm{L}$ (for concentrated feeding medium) of cheese whey powder (Elegê Laticínios S.A., Brazil) were dissolved in water and the $\mathrm{pH}$ adjusted to 4.5 with pure phosphoric acid. This solution was boiled during $10 \mathrm{~min}$ for protein precipitation and centrifuged at $15,000 \mathrm{~g}$ for $10 \mathrm{~min}$. The supernatant was then filtered. The permeate, which is the DCW, contained about $50 \mathrm{~g} / \mathrm{L}$ or $150 \mathrm{~g} / \mathrm{L}$ of lactose respectively. Supplementation studies were also carried out by the addition of $10 \mathrm{~g} / \mathrm{L}$ of yeast extract and 10 (M1), 20 (M2) or $30 \mathrm{~g} / \mathrm{L}$ (M3) of peptone. The $\mathrm{pH}$ of media were always adjusted to 6.0 with potassium hydroxide. For the bioreactor cultivations, $0.5 \mathrm{~mL} / \mathrm{L}$ of antifoam polyoxyethylene-polyoxypropylene copolymers (Mazu DF 800 S, Mazer Chemicals Ltd., England) was added to the final culture medium. 


\section{Bioreactor Cultivations}

Bioreactor experiments were performed in a $3 \mathrm{~L}$ stirred tank bioreactor (Biostat B, B.Braun Biotech International, Germany), filled with $1.5 \mathrm{~L}$ of culture medium. Culture conditions were $30{ }^{\circ} \mathrm{C}, 500 \mathrm{rpm}$, and aeration of $3 \mathrm{~L}$ air/min, previously described as the best growth conditions for the strain used in this work (Rech et al., 1999). Bioreactor was inoculated with $100 \mathrm{~mL}$ of a 30 hours pre-culture in YPL.

In the fed-batch cultures, feedings of 25,35 or 50 hours started after 24 hours of batch stage. The feeding followed the equation $\mathrm{F}=$ at, where $\mathrm{F}$ is the feeding $(\mathrm{mL} / \mathrm{min})$, $\mathrm{a}$ is the feeding constant coefficient $\left(\mathrm{mL} / \mathrm{min}^{2}\right)$ and $\mathrm{t}$ is feeding time $(\mathrm{min})$. The calculated coefficients for feedings of 25,35 or 50 hours were, respectively, $\mathrm{a}_{25 \mathrm{~h}}=8.889 \times 10^{-4}$ $\mathrm{mL} / \mathrm{min}^{2} ; \mathrm{a}_{35 \mathrm{~h}}=4.535 \times 10^{-4} \mathrm{~mL} / \mathrm{min}^{2} ;$ and $\mathrm{a}_{50 \mathrm{~h}}=$ $2.222 \times 10^{-4} \mathrm{~mL} / \mathrm{min}^{2}$. A total of $1000 \mathrm{~mL}$ of culture medium was fed.

Yields of biomass $\left(\mathrm{Y}_{\mathrm{X} / \mathrm{S}}\right)$, ethanol $\left(\mathrm{Y}_{\mathrm{EtOH} / \mathrm{S}}\right)$, and enzyme productivity $\left(\mathrm{Q}_{\mathrm{P}}\right)$ were calculated as described previously (Sinclair and Cantero, 1990).

\section{Enzyme Activity Assay}

$\beta$-galactosidase assay was carried out in cell-free extracts, using ONPG (o-nitrophenol- $\beta$-D-galactopyranoside) as substrate, and performed as described by Rech et al., 1999. A unit of enzyme activity was defined as the amount of enzyme required to liberate one $\mu \mathrm{mol}$ of ONP (o-nitrophenol) in one minute at the assay conditions.

\section{Biomass Concentration}

Cell concentration was spectrophotometrically determined at $\lambda=600 \mathrm{~nm}$ (Hitachi U-1100 spectrophotometer, Hitachi, Japan), and co-relating the readings to biomass dry weight with a calibration curve. The cells were harvested at 16,000 g for $3 \mathrm{~min}$ and washed twice with cold distilled water.

\section{Lactose Concentration}

Lactose was measured as total sugars, determined by a phenol sulphuric acid method as previously described (Rech et al., 1999).

\section{Ethanol Assay}

Ethanol concentration was determined by gas chromatography (CG-14B Shimadzu, Japan) properly set for this assay. To quantify the amount of ethanol, a calibration curve was constructed by adding a solution of cheese-whey $(70 \mathrm{~g} / \mathrm{L})$, varying ethanol concentrations, and using a fixed amount of n-propanol as internal standard.

\section{RESULTS AND DISCUSSION}

\section{Construction and Selection of a $S$. cerevisiae Strain that Produces $\beta$-Galactosidase}

S. cerevisiae W303 was co-transformed with the SmaI linearized plasmids pMR4 and pMR11. After incubation at $30{ }^{\circ} \mathrm{C}$ for 5 days, 39 colonies were isolated from lactose SD-agar plates and sequentially denominated BLR001 to BLR039. These colonies were tested on SD-agar plates containing glucose, maltose or lactose as carbon source. Only 25 colonies maintained the capacity to grow on lactose as the sole carbon source (BLR007 and BLR008, BLR012 to BLR019, BLR021, BLR023 and BLR024, BLR026 to BLR031, BLR033 to BLR036, BLR038 and BLR039). These 25 positive transformants were grown on YPL and the production of $\beta$-galactosidase was quantified, using $S$. cerevisiae W303 (the parental strain) and $\mathrm{K}$. marxianus CBS5665 as the negative and positive controls, respectively. Results represented in Figure 1a showed that strains BLR013, BLR015, BLR028, BLR035 and BLR036 presented poor growth, similar to the wild parental strain W303. The other strains had a similar growth profile, reaching around $10 \mathrm{OD}$ units, compared to K. marxianus that has grown to 25 OD units. Results for $\beta$-galactosidase activity (Figure $1 \mathrm{~b}$ ) show that strains BLR014, BLR029, BLR030, BLR033, BLR038 and BLR039 presented very high enzyme production, reaching up to four times that for $\mathrm{K}$. marxianus CBS6556. Strain BLR030 was finally chosen for bioreactor work. 

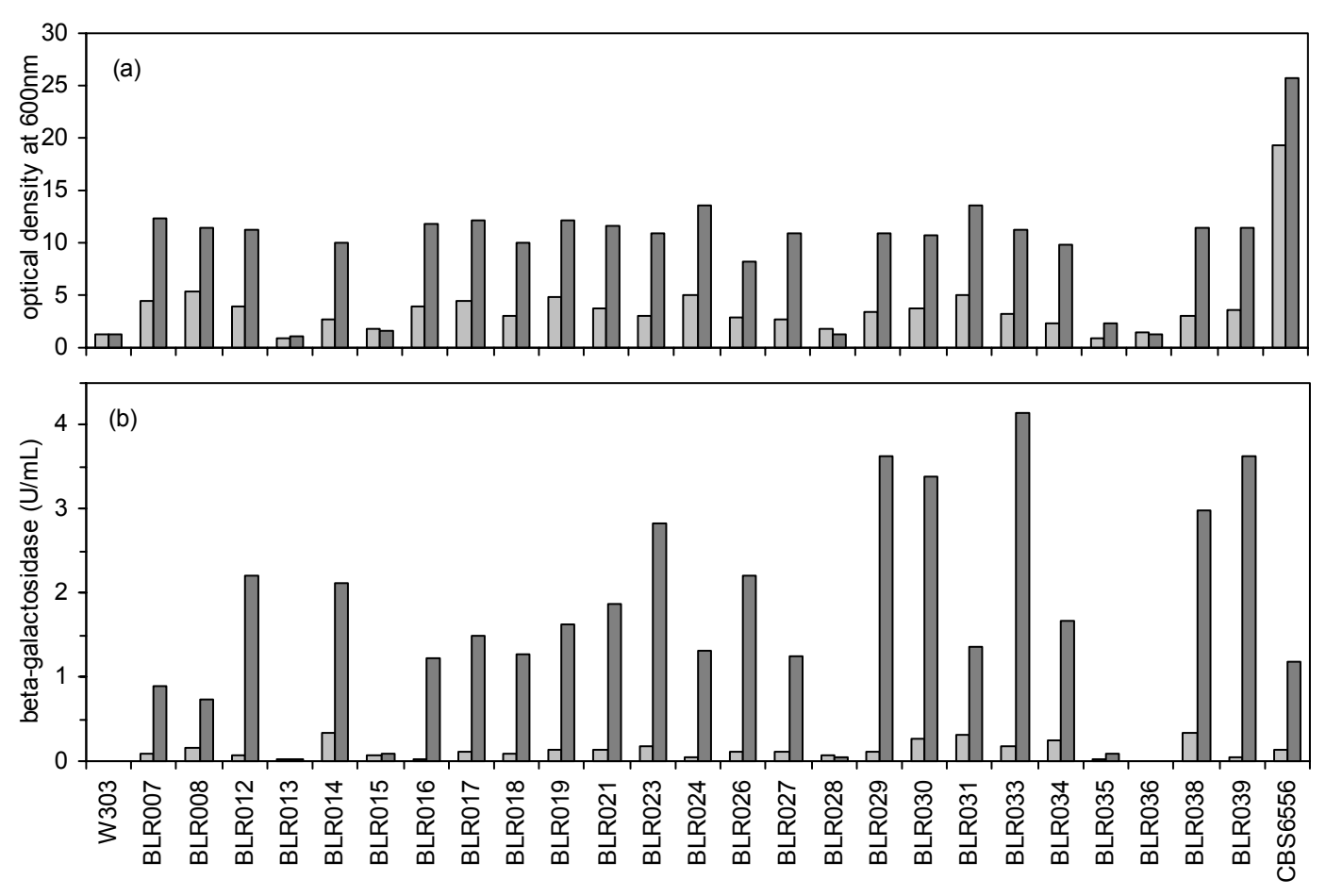

Figure 1: Growth (a) and $\beta$-galactosidase activity (b) of recombinant $S$. cerevisiae strains (BLR) compared with the wild strain (W303) and with K. marxianus CBS6556 in YPL at 24 hours ( $\square$ ) and 48 hours ( $\square$ ) of cultivation.

\section{Selection of Culture Medium for Fed-Batch Bioreactor Cultures}

These experiments were aimed to determine an efficient culture medium, based on DCW, for the growth of the recombinant $S$. cerevisiae BLR030 strain, and the production of $\beta$-galactosidase. Batch cultures with DCW containing about $50 \mathrm{~g} / \mathrm{L}$ of lactose were supplemented with $10 \mathrm{~g} / \mathrm{L}$ of yeast extract and 10 (M1), 20 (M2) or $30 \mathrm{~g} / \mathrm{L}$ (M3) of peptone. Biomass and $\beta$-galactosidase activity were measured at 24 and 48 hours, as presented in Table 1. This set of experiments was necessary to establish the amount of nitrogen source needed to support growth and enzyme production. Results have shown that medium M3 is the best composition for biomass and $\beta$-galactosidase production, thus being chosen for bioreactor experiments.

Table 1: Effect of medium composition on biomass formation and volumetric $\beta$-galactosidase activity of S. cerevisiae BLR030 growing on shake flasks. Data represent the mean of two experiments.

\begin{tabular}{|c|c|c|c|c|c|c|}
\hline \multirow[b]{2}{*}{ time } & \multirow[b]{2}{*}{ M1 } & \multicolumn{2}{|c|}{ Biomass (g/L) } & \multicolumn{3}{|c|}{$\beta$-gal (U/mL) } \\
\hline & & M2 & M3 & M1 & M2 & M3 \\
\hline $24 \mathrm{~h}$ & 1.12 & 1.23 & 1.31 & 1.17 & 1.53 & 1.87 \\
\hline $48 \mathrm{~h}$ & 2.47 & 3.40 & 4.17 & 2.36 & 2.86 & 8.34 \\
\hline
\end{tabular}

\section{Bioreactor Cultures}

In order to study the influence of the feeding time on fed-batch cultivations of $S$. cerevisiae BLR030, fed-batch cultures with linear ascending feeding profile of 25 (FB25), 35 (FB35), and 50 (FB50) hours were performed and the results were compared to the batch cultivation. Culture and feeding media were based on DCW enriched with yeast extract and peptone. Results are presented in Figures 2 (a), (b) and (c). Table 2 compares the values obtained for biomass and product yields of all cultures. Low biomass yields $\left(\mathrm{Y}_{\mathrm{X} / \mathrm{S}}\right)$ were obtained for batch and FB25. However, for 30 and 50 hours feedings, good 
biomass formation was obtained. Similar results were observed by Ramakrishnan and Hartley (1993) who grew aerobically $S$. cerevisiae GRF167 in lactose. Domingues et al. (1999) obtained small $\mathrm{Y}_{\mathrm{X} / \mathrm{s}}$ values in cultures of recombinant $S$. cerevisiae T1 growing in lactose minimal medium, suggesting that this medium composition does not make for a suitable medium to obtain high cell density cultures. Whenever achieved, high cell density cultures of $S$. cerevisiae always used complex defined media, with glucose or glucose and galactose combinations as carbon sources and some kind of sophisticated strategy to control substrate feeding according to the variations of cells metabolism during the fed-batch phase (Alberghina et al., 1991, Porro et al., 1991, Oh et al., 1998), however, these systems are based on expensive hardware and costly media.

Surprisingly, despite the strong aeration during all cultivations (oxygen concentration never felt below $50 \%$ saturation), a small amount of ethanol was always formed, about $10 \mathrm{~g} / \mathrm{L}$ (results not shown), indicating that, even under slow growth control, $S$. cerevisiae BLR030 was showing catabolic repression by lactose, a fermentative sugar that will trigger the Crabtree effect.

$\beta$-galactosidase specific activity, shown in Figure 2 (b), increased during the first hours after the feeding starts for all feeding strategies, between 30 and 50 hours of run, while cell growth was nearly absent (Figure 2 (a)), showing that the feeding with lactose induced $\beta$-galactosidase activity of cells. Similar results were obtained for K. marxianus CBS6556 in

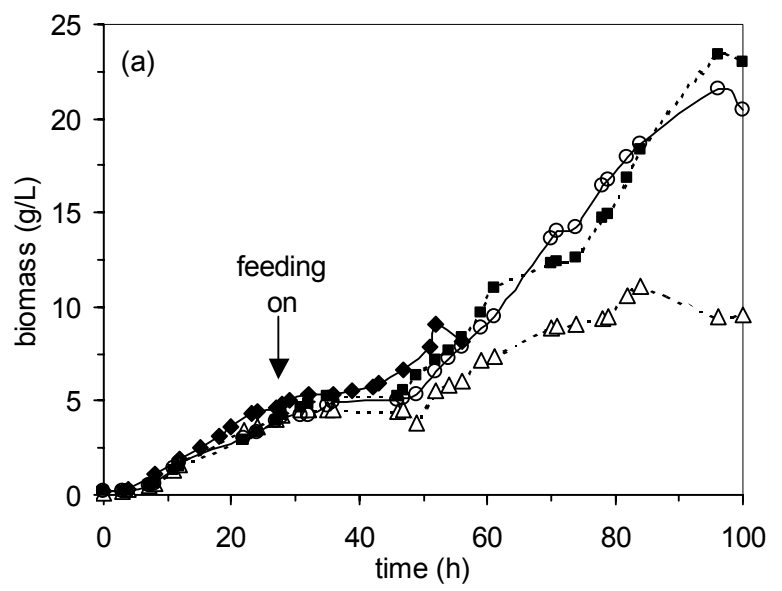

our previous work (Rech et al., 1999), suggesting that the mechanisms for enzyme production was similar for the recombinant strains of S. cerevisiae. The maximum specific activities were obtained at 49 hours of cultivation in FB35 and FB50 runs, with 1,778U/g cell and 1,934U/g cell, respectively. This specific activity is 2.8 times higher than that obtained in fed-batch cultures of K. marxianus CBS6556 using cheese-whey as culture medium and twice as high as obtained by Rubio-Teixeira et al. (1998) with $S$. cerevisiae MRY276, an haploid recombinant strain, but when they crossed MRY276 with S288C, a wild strain of $\mathrm{S}$. cerevisiae, the specific $\beta$-galactosidase activity of the diploid strain raised 4 folds. These experiments were carried out in batch cultures using defined complex medium containing lactose as the carbon source instead of cheese-whey, as is the case in our work. $\beta$-galactosidase volumetric activities shown in Figure 2 (c), and the productivity values $\mathrm{Q}_{\mathrm{P}}$ (Table 2) confirms that there are no important differences between feeding for 35 or 50 hours: 180 and 185U/L.h, respectively. Although volumetric activities were similar to those obtained for $\mathrm{K}$. marxianus growing under the same feeding strategies and medium, the productivities are about $35 \%$ lower (Rech et al., 1999). This fact can be explained by the lower growth rates of the recombinant $S$. cerevisiae obtained in this work, consequently imposing longer cultivation times. However, it is interesting to note that $S$. cerevisiae and $\mathrm{K}$. marxianus batch cultivations have similar productivities: 120 and 118U/L.h, respectively.

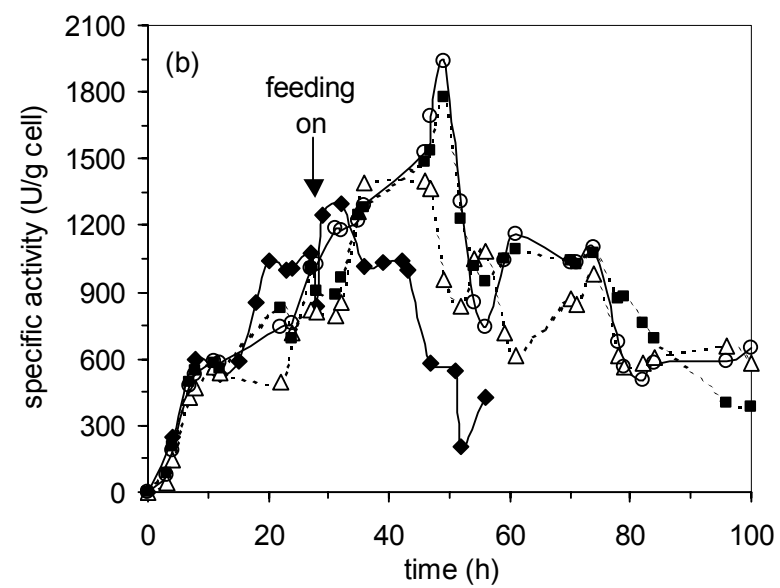




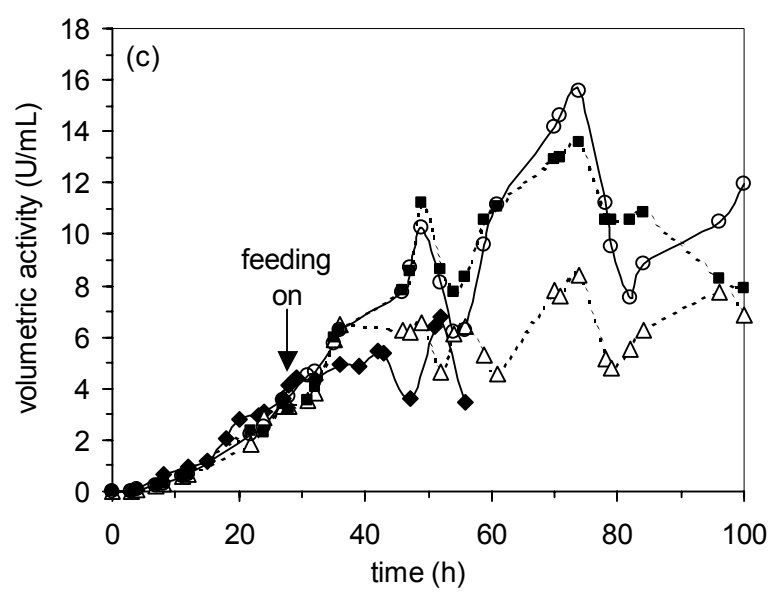

Figure 2: Time course for batch $(\longrightarrow-)$ and fed-batch bioreactor cultivation of recombinant $S$. cerevisiae BLR030 with linear ascending feeding profile for 25 hours $(\cdots \Delta \cdots), 35$ hours $(-\varnothing)$ and 50 hours $(\cdots \cdots)$.

(a) biomass; (b) $\beta$-galactosidase specific activity; (c) $\beta$-galactosidase volumetric activity.

(b) Experiments are the mean of three cultivations.

Table 2: Yields and productivities for batch and fed batch cultivations of S. cerevisiae BLR030 growing on shake flasks. Data represent the mean of two experiments.

\begin{tabular}{|l|c|c|c|c|}
\hline & Batch & FB25 & FB35 & FB50 \\
\hline $\mathrm{Y}_{\mathrm{X} / \mathrm{S}}$ & 0.18 & 0.16 & 0.23 & 0.26 \\
$\mathrm{Y}_{\mathrm{EtOH} / \mathrm{S}}$ & & 0.05 & 0.05 & 0.06 \\
$\mathrm{Q}_{\mathrm{P}}(\mathrm{U} /$ (L.h) $)$ & 120 & 125 & 180 & 185 \\
\hline
\end{tabular}

\section{CONCLUSIONS}

The construction of recombinant strains of $S$. cerevisiae as host for heterologous protein expression has been widely used in research and starts now being used in industrial processes. The insertion of LAC4 and LAC12 into the genome of S. cerevisiae, under the control of a strong promoter such as the one used in this work (CYC-GAL) is a promising strategy to allow the use of this well known and safe yeast in cultures based on lactose, a sugar that is not normally metabolised by $\mathrm{S}$. cerevisiae. In this way, large amounts of cheese whey, a by-product of dairy industry, can then be used as an inexpensive carbon source for cell cultivation in order to reduce costs of enzyme productions, although some supplementation with yeast extracts and peptone might be necessary. Moreover, we developed a simple feeding strategy, not relying on sophisticated control systems. The results showed promising perspectives for further developments, if we consider that higher volumetric and specific enzyme activities were obtained when compared to cultures of $\mathrm{K}$. marxianus growing under the same conditions and medium.

\section{REFERENCES}

Agatep, R., Kirkpatrick, R.D., Parchaliuk, D.L., Woods, R.A. and Gietz, R.D., Transformation of Saccharomyces cerevisiae by the lithium acetate/single-stranded carrier DNA/polyethylene glycol (LiAc/ss-DNA/PEG) protocol. Technical Tips Online (BPhttp://tto.trends.comBP) (1998).

Alberghina, L., Porro, D., Martegani, E. and Ranzi, B.M., Efficient production of recombinant DNA proteins in Saccharomyces cerevisiae by controlled high-cell-density fermentation. Biotechnology and Applied Biochemistry 14, 82-92 (1991).

Barberis, S.E. and Segovia, R.F., Dissolved oxygen concentration-controlled feeding of substrate in to Kluyveromyces fragilis culture. Biotechnology Techniques 11, 797-799 (1997).

Belem, M.A.F. and Lee, B.H., Fed-batch fermentation to produce oligonucleotides from Kluyveromyces marxianus grown on whey. Process Biochemistry 34, 501-509 (1999).

Borsig, L., Ianov, S.X., Herrmann, G.F., Kragl, U., WanUdrey, C. and Berger, E.G., Scaled-up expression of human $\alpha-2,6(\mathrm{~N})$ sialyltransferase in Saccharomyces cerevisiae. Biochemical and 
Biophysical Research Communications 210, 14-20 (1995).

Calado, C.R.C., Taipa, M.Â., Cabral, J.M.S. and Fonseca, L.P., Optimisation of culture conditions and characterisation of cutinase produced by recombinant Saccharomyces cerevisiae. Enzyme and Microbial Technology 31, 161-170 (2002).

Chen, C.W., Lei, B.C., Yeh, K.W. and Duan, K.J., Recombinant sweet potato sporamin production via glucose $/ \mathrm{pH}$ control in fed-batch cultures of Saccharomyces cerevisiae. Process Biochemistry, 38, 1223-1229 (2003).

Cheng, C., Hunag, Y.L. and Yang, S.T., A novel feeding strategy for enhanced plasmid stability and protein production in recombinant yeast fermentation. Biotechnology and Bioengineering 56, 25-31 (1997).

Domigues, L., Teixeira, J.A. and Lima, N., Construction of a flocculent Saccharomyces cerevisiae fermenting lactose. Applied Microbiology and Biotechnology 51, 621-626 (1999).

Gombert, A.K. and Kilikian, B.V., A simple way of achieving a high cell concentration in recombinant Escherichia coli cultivation. Brazilian Journal of Chemical Engineering 14, (1997).

González-Siso, M.I., The biotechnological utilization of cheese whey: a review. Bioresource Technology 57, 1-11 (1996).

Hale, A.D., Bartkevičiūte, D., Dargevičiūtè, A., Jin, L., Knowles, W., Staniulis, J., Brown, D.W.G. and Sasnauskas, K., Expression and antigenic characterization of the major capsid proteins of human polyomaviruses BK and JC in Saccharomyces cerevisiae. Journal of Virological Methods 104, 93-98 (2002).

Hardjito, L., Greenfield, P.F. and Lee, P.L., Recombinant protein production via fed-batch culture of the yeast Saccharomyces cerevisiae. Enzyme and Microbial Technology 15, 120-126 (1993).

Horn, U., Strittmatter, W., Kreber, A., Knüpfer, U., Kujau, M., Wenderoth, R., Müller, K., Matzku, S., Plückthun, A. and Reisenberg, D., High volumetric yields of functional dimeric miniantibodies in Escherichia coli, using an optimized expression vector and high-cell-density fermentation under non-limited growth conditions. Applied Microbiology and Biotechnology 46, 524-532 (1996).

Kim, M.D., Han, K.C., Kang, H.A., Rhee, S.K. and Seo, J.H., Coexpression of BiP increased antithrombotic hirudin production in recombinant
Saccharomyces cerevisiae. Journal of Biotechnology 101, 81-87 (2003).

Lim, Y.Y., Lee, M.Y., Chung, B.W., Park, S.M., Park, S.G., Jang, Y.S., Yang, M.S. and Kim, D.H., Expression of a functional human interleukin-18 in yeast. Enzyme and Microbial Technology 30, 703-709 (2002).

Nor, Z.M., Tamer, M.I., Scharer, J.M., Moo-Young, M. and Jervis, E.J., Automated fed-batch culture of Kluyveromyces fragilis based on a novel method for on-line estimation of cell specific growth rate. Biochemical Engineering Journal 9, 221-231 (2001).

Oh, G., Moo-Young, M. and Chisti, Y., Automated fed-batch culture of recombinant Saccharomyces cerevisiae based on on-line monitored maximum substrate uptake rate. Biochemical Engineering Journal 1, 211-217 (1998).

Park, S., Jeong, H.Y., Kim, H.S., Yang, M.S. and Chae, K.S., Enhanced production of Aspergillus ficuum endoinulinase in Saccharomyces cerevisiae by using the SUC2-deletion mutation. Enzyme and Microbial Technology 29, 107-110 (2001).

Patkar, A. and Seo, J.H., Fermentation kinetics of recombinant yeast in batch and fed-batch cultures. Biotechnology and Bioengineering 40, 103-109 (1992).

Porro, D., Martegani, E., Tura, A. and Ranzi, B.M., Development of a $\mathrm{pH}$-controlled fed-batch system for budding yeast. Research in Microbiology 142, 535-539 (1991).

Pushnova, E.A., Ostanin, K. and Thelen, M.P., Human XPA and XRCC1 DNA Repair Proteins Expressed in Yeast, Saccharomyces cerevisiae. Molecular Genetics and Metabolism 74, 380-384 (2001).

Ramakrishnan, S. and Hartley, B.S., Fermentation of lactose by yeast cells secreting recombinant fungal lactase. Applied and Environmental Microbiology 59, 4230-4235 (1993).

Rech, R., Cassini, C.F., Secchi, A. and Ayub, M.A.Z, Utilization of protein hydrolyzed cheese-whey for production of $\beta$-galactosidase by Kluyveromyces marxianus. Journal of Industrial Microbiology and Biotechnology 23, 91-96 (1999).

Rubio-Teixeira, M., Arévalo-Rodríguez, M., Lequerica, J.L. and Polaina, J., Lactose utilization by Saccharomyces cerevisiae strains expressing Kluyveromyces lactis LAC genes. Journal of Biotechnology 84, 97-106 (2000).

Rubio-Teixeira, M., Castrillo, J.I., Adam, A.C., Ugalde, U.O. and Polania, J., Highly efficient 
assimilation of lactose by a metabolically engineered strain of Saccharomyces cerevisiae. Yeast 14, 827-837 (1998).

Saffi, J., Feldmann, H., Winnacker, E.L. and Henriques, J.A.P., Interaction of the yeast Pso5/Rad16 and Sgs1 proteins: influences on DNA repair and aging. Mutation Research/DNA Repair 486, 195-206 (2001).

Sekimoto, H., Production and secretion of a biologically active Closterium sex pheromone by Saccharomyces cerevisiae. Plant Physiology and Biochemistry 40, 789-794 (2002).

Shin, C.S., Hong, M.S., Kim, D.Y., Shin, H.C. and Lee, J., Growth-associated synthesis of recombinant human glucagon and human growth hormone in high-cell-density cultures of
Escherichia coli. Applied Microbiology and Biotechnology 49, 364-370 (1998).

Sinclair, C.G. and Cantero, D., Fermentation modeling. In Fermentation: a practical approach. Ed. B. McNeil and L.M. Harvey. Oxford University Press, Oxford, 1990, pp. 65-112.

Tamer, I.M. and Chisti, Y., Production and recovery of recombinant protease inhibitor $\alpha_{1}$-antitrypsin, Enzyme and Microbial Technology 29, 611-620 (2001).

Ueda, M., Takahashi, S., Washida, M., Shiraga, S. and Tanaka, A., Expression of Rhizopus oryzae lipase gene in Saccharomyces cerevisiae. Journal of Molecular Catalysis B: Enzymatic 17, 113-124 (2002).

USDA-NASS, 2002 http://www.usda.gov/nass/pubs/ Agr02/02ch8.pdf in26/11/02 